\title{
O CUIDAR EM ENFERMAGEM À MULHER VÍTIMA DE VIOLÊNCIA SEXUAL ${ }^{1}$
}

\author{
Sheila Coelho Ramalho Vasconcelos Morais², Claudete Ferreira de Sousa Monteiro³, Silvana Santiago \\ da Rocha ${ }^{4}$
}

\footnotetext{
${ }^{1}$ Recorte da dissertação - O Cuidar de Enfermagem à Mulher Vítima de Violência Sexual, Programa de Pós-Graduação em Enfermagem da Universidade Federal do Piauí (UFPI), 2008.

${ }^{2}$ Mestre em Enfermagem. Docente do Departamento de Enfermagem da UFPI. Piauí, Brasil. E-mail: sheilacoelhorvm@hotmail. com

${ }^{3}$ Doutora em Enfermagem. Docente do Departamento de Enfermagem da UFPI. Piauí, Brasil. E-mail: claudetefmonteiro@ hotmail.com

${ }^{4}$ Doutora em Enfermagem. Docente do Departamento de Enfermagem da UFPI. Piauí, Brasil. E-mail: silvanasantiago27@gmail. com
}

RESUMO: O propósito deste ensaio é refletir acerca do cuidar em enfermagem à mulher vítima de violência sexual, nas dimensões: técnica, de acolhimento e da existência humana, pautada em conceitos filosóficos e de estudiosas da área de enfermagem. A partir deste estudo, aponta-se que o cuidar realizado pela enfermagem à vítima de violência sexual, ainda é centrado no modelo tecnicista e que esse cuidar deve ser ampliado para uma ação acolhedora e humana, possibilitando uma relação de partilha de valores e emoções entre o ser cuidador e o ser cuidado, com uma atenção que transcenda o sentido de curar e tratar, contemplando com atitudes de solicitude, paciência e preocupação.

DESCRITORES: Violência sexual. Violência contra a mulher. Enfermagem.

\section{NURSING CARE FOR SEXUALLY VIOLATED WOMEN}

\begin{abstract}
The intention of this assay is to reflect upon nursing care for sexually violated women within the following dimensions: technical, sheltering, and the human existence, based on philosophical concepts and nursing studies. This study points out that nursing care for a victim of sexual violence is still centered in the technical model and that this care must be extended towards actions of shelter and humanity, making a relationship of sharing values and emotions between the caregiver and the care receiver possible, with an attention that exceeds the sense of curing and treating, contemplating thoughtful attitudes, patience, and concern.
\end{abstract}

DESCRIPTORS: Sexual violence. Violence against woman. Nursing.

\section{EL CUIDAR EN ENFERMERÍA A LA MUJER VÍCTIMA DE VIOLENCIA SEXUAL}

RESUMEN: El propósito de este ensayo es reflexionar acerca del cuidar en enfermería a la mujer víctima de violencia sexual, en las siguientes dimensiones: técnica, de acogida y de la existencia humana, el cual se basa en conceptos filosóficos y del área de enfermería. Con este estudio se muestra que el cuidado realizado por la enfermería a la víctima de violencia sexual sigue centrado en el modelo técnico y que ese cuidado debería extenderse a una acción acogedora y humana que permita una relación compartida de valores y emociones entre el cuidador y el ser que es cuidado, con una atención que trascienda el sentido de curar y tratar, que comprende las actitudes de atención, paciencia y preocupación.

DESCRIPTORES: Violencia Sexual. Violencia contra la mujer. Enfermería. 


\section{INTRODUÇÃO}

A enfermagem, como ciência do cuidar, vem, ao longo das últimas décadas, buscando aprofundar discussões sobre sua prática, reconhecendo que o cuidar é um processo e, dessa forma, em evolução e sujeito às mudanças que ocorrem no sistema de saúde e no modo de significância para o ser cuidado. ${ }^{1}$

Entre aqueles a serem cuidados, está a mulher que foi violentada sexualmente, violência que tem sido apontada como um problema histórico, social e mundial, que tem aumentado de maneira assustadora, tornando-se motivo de preocupação dos países, de estudiosos, de autoridades, de organizações não-governamentais e por vários campos do conhecimento. ${ }^{2-3}$

A mulher, por ser alvo preferencial desse tipo de violência, tem merecido a atenção por parte de profissionais, principalmente os de enfermagem que, na sua trajetória prática e em qualquer ambiente de trabalho, podem defrontar-se com essa situação, exigind o conhecimento específico e habilidade para realizar esse cuidar como expressão humanizadora da enfermagem, com poder transformador, que deve ser sentido e vivido por parte de quem cuida e de quem é cuidado.

Nessa concepção, o primeiro contato da mulher no serviço de saúde deve acontecer com os profissionais de enfermagem, que farão um acolhimento humanizado, a realização da anamnese, coleta de material para exames laboratoriais, agendamento de retorno e administração de medicações. Esses são passos que garantem a aderência ao seguimento ambulatorial. ${ }^{4}$

No entanto, a prática tem mostrado que ainda se faz necessário discutir os modos de cuidar em enfermagem à mulher vítima de violência sexual, para buscar aprofundar conhecimentos que reflitam o exercício de enfermagem - sobre o que fazer? Como fazer? e por que fazer? - de modo que esse atendimento se faça de forma singular e específica.

Nesse sentido, se propõe refletir acerca do cuidar em enfermagem à mulher vítima de violência sexual nas dimensões: técnica, de acolhimento e da existência humana, a partir de conceitos de estudiosas e teóricas de enfermagem que tratam a questão do cuidar, bem como, de pensadores filosóficos, como Leonardo Boff e Martin Heidegger, que têm apontado o cuidado como elemento primordial para a existência humana.
O CUIDAR EM ENFERMAGEM NA DIMENSÃO TÉCNICA

Na busca de apresentar o cuidar na dimensão técnica, nos apoiamos na compreensão da habilidade técnica do profissional de enfermagem em saber-fazer os cuidados à mulher vítima de violência sexual em conformidade com a Norma Técnica (NT) do Ministério da Saúde (MS), sendo medidas preventivas que a mulher dispõe para evitar uma gravidez indesejada e o aparecimento das doenças sexualmente transmissíveis.

Nessa ação, a mulher ao buscar o serviço de saúde, recebe uma assistência que envolve outros profissionais, como médico legista e ginecologista, assistente social, psicólogo, que em conjunto planejam o tratamento dos agravos que podem ser imediatos ou a longo prazo, de ordem física e psicológica. Os agravos físicos são decorrentes do trauma genital, evidenciado por lacerações, hematomas, equimoses e edemas, principalmente nas mulheres de maior idade, e nos casos das crianças vitimizadas, que podem ainda apresentar lesões na vagina, no períneo, no ânus e no reto. ${ }^{5-6}$ Já nos casos de lesões extragenitais, encontram-se escoriações, equimoses e fraturas da face. Além dessas lesões, as vítimas podem apresentar distúrbios emocionais, como insônia, pesadelo, depressão, fobias, pânico, ansiedade, medo da morte, sensação de solidão, cefaléia, fadiga, transtorno do apetite, risco para uso de drogas ilícitas e suicídio, pois em algumas situações a severidade da agressão da violência sexual é conjugada com relações anais e orais. ${ }^{6-7}$

Compreende-se que nessa ação do cuidar realizado pela enfermagem em conformidade com a NT/MS, direciona-se para um saber técnico, em que suas ações estão voltadas para o tratamento das lesões, prevenções das Doenças Sexualmente Transmitidas (DSTs) e da hepatite B, bem como para a prevenção de uma gravidez indesejada. Assim, a assistência de enfermagem à mulher vítima de violência sexual antecede a uma prescrição médica, para que seja feita a administração de medicamentos no sentido de diminuir os riscos de adquirir DSTs, por infecção pela Neisseria gonorrhoeae de 0,8 e 9,6\%; como para o Trichomonas vaginallis de 3,1 a $22 \%$; seguido de Chlamydia trachomatis de 1,5 a $26 \%$; para vaginose bacteriana entre 12 a 50\%; do Papiloma Vírus Humano (HPV) de 2 a $40 \%$; para Treponema pallidum é de até 1,6\% e para hepatite B de $3 \%$. Enquanto que para a transmissão do Vírus da Imunodeficiência Humana (HIV) é menos de $1 \% .^{8}$ 
Dessa forma, percebe-se que essa ação de cuidar à mulher vítima de violência sexual pela enfermagem no serviço de saúde segue o modelo biomédico, em que as ações assistenciais estão direcionadas para o fazer, justificando a predominância do cuidado na dimensão técnica. Assim, acreditamos que a própria evolução histórica da profissão de enfermagem, associado ao avanço tecnológico e científico, tenha contribuído para um modo de fazer que se configura em intervenções, sem a incorporação da subjetividade na relação entre o ser cuidado e o ser cuidador.

Na busca de expressar as finalidades do cuidar de enfermagem para além de ações técnicas, deve-se priorizar " [...] aliviar o sofrimento humano, manter a dignidade e facilitar meios para manejar com as crises e com as experiências do viver e do morrer" 1:90 Contudo, o cuidado como fenômeno responsável pela humanização tem sido anunciado com o propósito de unir o cuidado técnico ao cuidado humano, isso se comprova quando os estudos produzidos pelas enfermeiras através de pesquisas, dissertações e teses, desde a década de 1990, têm enfatizado a prática de enfermagem técnica e científica associada ao cuidado afetivo-expressivo, demonstrando assim, o cuidado humanizado. ${ }^{1,9}$ Com esse pensar corroboram outros estudos, ao reafirmarem que a expansão da produção científica e das discussões sobre o cuidado humanizado tem sido a tradução epistemológica da expressão da enfermagem. ${ }^{10}$

Portanto, o cuidar em enfermagem à mulher na situação de violência sexual na dimensão técnica volta-se para uma ação que exige um domínio da habilidade do profissional, ou seja, no saber-fazer. Entretanto, é nessa relação do ser cuidador e do ser cuidado, que se incorpora a intersubjetividade, no momento em que é estabelecida uma interação através da linguagem. Assim, esse cuidar técnico em enfermagem também permite uma aproximação do ser na sua existência humana.

\section{O CUIDAR EM ENFERMAGEM NA DI- MENSÃO DO ACOLHIMENTO}

O acolhimento como uma dimensão do cuidar é apresentado a partir de conceitos elaborados por estudiosas na área de enfermagem que vêm se preocupando com o distanciamento do ser cuidador com o ser cuidado. Esta reflexão traz a possibilidade de realizar o cuidar em enfermagem à mulher vítima de violência sexual numa perspectiva técnica associada às ações humanizadoras, no sentido de acolher, ouvir, tocar e silenciar.
Assim, o cuidar em enfermagem como uma ação na dimensão do acolhimento pode ser vivenciado pelo profissional e pela vítima de violência sexual, desde o momento da entrada no serviço de atendimento, percorrendo todo o processo assistencial realizado. Nesse sentido, o cuidado de enfermagem e dos demais profissionais a essa clientela é assegurado de forma que a vítima e a família sintam-se protegidas e seguras no atendimento prestado, na garantia do sigilo e dos encaminhamentos adequados. ${ }^{11}$

$\mathrm{O}$ significado do cuidar em enfermagem como uma ação acolhedora se refere à qualidade e humanização da atenção como um conjunto de medidas, posturas e atitudes dos profissionais de saúde na sua relação com o cliente..$^{12}$ No caso da enfermagem, significa compreender o indivíduo em sua plenitude, ouvi-lo com sensibilidade, criatividade e solidariedade, o que caracteriza a qualidade do cuidado. Sendo assim, a prática do acolhimento no trabalho de enfermagem é no sentido de realizar atitudes humanizadoras que se revelam no ato de receber, escutar e tratar..$^{13}$

Outro entendimento da palavra acolhimento perpassa pela postura, e pelo princípio de reorientação de serviços. Portanto, no momento que o profissional de saúde adota a postura de acolher, pressupõe uma atitude receptiva para escutar de forma sensível a individualidade de cada ser. Enquanto acolhimento, na perspectiva técnica significa instrumentalizar os procedimentos e ações organizadas para o processo de trabalho. Oúltimo conceito é no sentido de organização do serviço, para nortear e gerenciar todo o processo de trabalho. ${ }^{14}$

Dessa forma, entendemos que o cuidar em enfermagem à mulher vítima de violência sexual exige mais do que as habilidades técnicas, requerendo uma atenção individualizada que transcenda o sentido de curar e tratar. Portanto, desde o momento em que a mulher em situação de violência sexual procura o serviço de saúde especializado, o profissional de enfermagem tem a oportunidade de acolher a mulher e mostrar a verdadeira essência da sua profissão, o cuidar/ cuidado. Acerca dessa questão, o cuidar em enfermagem como ação de acolhimento poderá se concretizar, no momento em que se adota uma atitude de escuta e de silêncio.

A idéia de cuidar esteve presente desde o início da espécie humana como modo de sobrevivência e como forma de interesse e carinho, considerado como elemento primordial para a evolução humana e parte essencial da sua existência. ${ }^{1}$ En- 
tender esse cuidado em sua perspectiva histórica, é proporcionar uma reflexão sobre a existência do humano, no sentido de compreendê-lo em suas relações, anseios, dúvidas e necessidades. ${ }^{15}$

Por conseguinte, infere-se que o cuidar é indispensável para a existência humana e que ele é desvelado no processo de viver e de sobreviver. Nessa perspectiva, a enfermagem ao realizar o cuidado à mulher vítima de violência sexual, tem a possibilidade de descortinar outros problemas que possam afetar a integridade física e emocional dessa mulher. Assim, o profissional de enfermagem, ao adotar a postura de ouvir a mulher que busca o serviço de saúde, com suas queixas variadas, tem nesse momento, condições de rastrear situações de violência que estejam contidas no silêncio, no medo e na vergonha.

As concepções apresentadas sobre acolhimento permeiam um conceito de ouvir, de tocar e de receber, bem como elemento essencial para a reorganização do trabalho, com a finalidade de humanizar as ações prestadas no serviço de saúde. Assim, para que exista o ser-enfermagem, é indispensável a presença do outro ser humano, pois nesse encontro há a possibilidade de estabelecer-se uma relação afetiva em que os sentimentos vivenciados e experienciados pelo ser-no-mundo seja um encontro de cuidado autêntico. ${ }^{16}$

Logo, esse cuidar acolhedor pela enfermagem permite um olhar sensível e humano para a saúde da mulher vítima de violência sexual, com a finalidade de recuperar sua autoestima, sua saúde mental e sua qualidade de vida.

\section{O CUIDAR EM ENFERMAGEM NA DI- MENSÃO DA EXISTÊNCIA HUMANA}

Entendendo que o cuidar é elemento primordial para a existência humana, a sua compreensão tem como referencial teórico as reflexões de autoras e teóricas de enfermagem como, Jean Watson, Paterson e Zderad, além de pensadores filosóficos, como Leonardo Boff e Martin Heidegger.

O conceito apresentado sobre cuidar em enfermagem na perspectiva da dimensão da existência humana, se processa no encontro entre o ser cuidador e o ser cuidado, cujos objetivos envolvem o conforto, ajuda, promoção, restabelecimento, no sentido de aliviar o sofrimento humano. ${ }^{1}$

Nesse momento de relacionamento interpessoal, o cuidar em enfermagem emerge através dos atos humanos no processo de assistir a pessoa baseado no sentimento de ajuda, confiança, empatia mútua, nos valores humanísticos e também no conhecimento científico. ${ }^{17}$ Assim, o cuidado é entendido como elemento primordial para a existência humana, a partir do modo de ser-aí, com base no pensamento do filósofo Martin Heidegger.

Para o filosófico Leonardo Boff, o significado de cuidar implica em duas definições, a primeira como gesto de desvelo, de solicitude e de atenção, e como segunda, refere-se à preocupação e inquietação. Também traz para a reflexão que o cuidado é mais do que um ato, é uma atitude. O filósofo recorre ao pensamento de Martin Heidegger ao explanar a natureza do cuidado como o modo de ser e de solicitude, por permitir uma relação de preocupação, guiada pela consideração e pela tolerância. ${ }^{18}$

$\mathrm{Na}$ enfermagem, essa discussão tem também as contribuições valiosas das teorias de Jean Watson e de Paterson e Zderad. Na perspectiva de Jean Watson, o cuidado é entendido numa abordagem humanística e comportamental, na qual a enfermagem consiste na ciência e na filosofia do cuidado e, para tal, precisa ter o cultivo da sensibilidade, da autoconfiança, da promoção e aceitação de sentimentos positivos e negativos, utilização de um processo de cuidar criativo de resolução de problemas, assistir nas necessidades humanas e admitir forças existenciais, fenomenológicas e espirituais nesse cuidar. Dessa forma, o fundamento sólido para a ciência do cuidado está pautado na habilidade do pensamento crítico e da visão expandida do mundo, por enfocar mais a promoção da saúde do que a cura. ${ }^{19}$

Tomando por base a teoria de Jean Watson, o cuidar em enfermagem à mulher vítima de violência sexual pode ser planejado a partir do momento em que se estabelece um vínculo do ser cuidador com o ser cuidado numa perspectiva humanística, que focalize a unicidade do ser na sua facticidade. ${ }^{18}$ Assim, o profissional de enfermagem, ao receber a mulher nessa situação deve lançar mão da subjetividade para atender as necessidades humanas dessa vítima. Nesse momento, essa ação coliga o fazer tecnicista a um fazer humanitário, pois permite que o profissional de enfermagem compreenda os sentimentos negativos expressos naquela ocasião tão singular.

A teoria de Paterson e Zderad tem como foco central a Enfermagem Humanística, pois se preocupa com as experiências fenomenológicas vividas pela enfermeira e pela pessoa que recebe o cuidado. É uma metodologia para compreender e descrever as situações de enfermagem, numa abordagem filosófica da fenomenologia e do exis- 
tencialismo. ${ }^{20}$ Desse modo, a enfermagem busca compreender a experiência da relação entre o ser-enfermeiro e o ser-cliente, de maneira que esse estar-com seja humano e curativo. A abordagem existencial-fenomenológico-humanística, “[...] valoriza a necessidade de interação humana para determinar o significado que vem da forma exclusiva de o indivíduo experimentar o mundo" ${ }^{19: 242}$

Nesse sentido, a reflexão desse cuidar à mulher vítima de violência sexual pela enfermagem, a partir da teoria humanística, vislumbra uma prática que valorize o significado da experiência vivida pelo ser que cuida e pelo ser cuidado. Desta forma, quando o profissional compartilha dessa experiência de cuidar no seu cotidiano com quem cuida, permite uma transação intrahumana permeada pela intersubjetividade com a finalidade de compreender o outro, como um ser em potencial. Para a receptora desse cuidar, essa relação estabelecida proporciona o expressar de seus sentimentos e comportamentos negativos.

As colaborações das teóricas citadas são fundamentais para a compreensão do cuidado na dimensão da existência humana, mas entendemos que é com o pensamento filosófico de Martin Heidegger que essa compreensão se torna plena em virtude de ser reconhecido como o Filósofo do Cuidado. O filósofo alemão considera o cuidar/ preocupação como um dispositivo fundamental para lidar com o mundo. ${ }^{15}$

O cuidado a que Heidegger se refere se mostra, portanto, a partir do relacionar-se com o outro e se manifesta na relação do ser-aí com o ser-nomundo, guiado pela consciência e pela paciência. Para Heidegger, o ser-aí significa Dasein, que é o modo de existir do homem, que constrói o seu modo de ser, a sua existência e historicidade a partir da presença. Assim, todo ser é sempre ser-com, pois o mundo é sempre mundo compartilhado e de convivência, e é nas relações do Dasein, com ser-no-mundo, que emerge o cuidado..$^{21-22}$

Nesse relacionar-se, a maneira de cuidar do outro é entendida como solicitude, é ter consideração, paciência e preocupação com o outro, sob duas formas básicas de cuidado, o dominador e o libertador. No pensamento heideggeriano, o termo consideração é entendido como aceitação das tensões, limites e as características diferenciais das situações e modos de ser, enquanto que tolerância pressupõe uma expectativa de algo que possa vir a acontecer..$^{23}$

Conforme entendimento, o filósofo apresenta os modos positivos de preocupação em duas possibilidades. A primeira se refere à preocupação no sentido de ocupar o lugar do outro no tocante à realização do seu cuidado, que pode ser dependente e dominado, mesmo que ele não perceba, uma vez que esse cuidar se manifeste de forma silenciosa e encoberta. Consoante dito, a preocupação traduz-se numa relação substitutiva ligada à atuação profissional. A preocupação também diz respeito a não retirar-lhe o cuidado, mas sim devolvê-lo, "[...] no sentido de ajudar o outro a tornar-se, em sua cura, transparente a si mesmo e livre para ela". ${ }^{23: 179}$ Desta forma, realizar o cuidar em enfermagem à mulher vítima de violência sexual, numa abordagem heideggeriana, é resgatar um cuidado autêntico que se revela no momento em que esse profissional interage com essa mulher e a ajuda a se ver como ser de possibilidade e compreender que é possível ultrapassar essa facticidade e dela retirar modos de superação para se compreender como além daquilo que ela própria não se compreendia. Nessa transação subjetiva, esse cuidar pela enfermagem pode acontecer de forma factível, necessitando da habilidade técnica e científica aliada a um preparo emocional para aceitar as tensões e a existencialidade de cada ser naquele momento.

Diante dessas colocações, e na compreensão do pensar de vários autores que discutem o cuidar, percebe-se que - na evolução da prática profissional da enfermagem - tem prevalecido o cuidado técnico, resultando no distanciamento do cliente, o que remete à necessidade do resgate desse cuidar na abrangência de sua dimensão que interagindo com essas mulheres que passam por momentos de profunda angustia vêem-se abusivamente corrompidas naquilo que as machucam intimamente e sem autorização.

\section{CONSIDERAÇÕES FINAIS}

Podemos concluir que o cuidar em enfermagem à mulher vítima de violência sexual leva à compreensão de que as ações dos profissionais de enfermagem estão centradas em sua maior parte no cuidado técnico, pautado na normatização do MS, embora haja a necessidade de incorporar na prática cotidiana, o cuidar na dimensão acolhedora e humana, permitindo uma relação de partilha de valores e emoções.

Assim, apontamos possibilidades de outras dimensões do cuidar, a partir de atitudes acolhedoras e humanizadoras que se revelam no ato de receber, ouvir, tocar e tratar, bem como uma relação autêntica entre o ser que cuida e o ser cuidado. 
Portanto, infere-se a partir dessa reflexão de que realizar esse cuidar à mulher vítima de violência sexual pela enfermagem requer ainda uma assistência além da tecnicista, que esteja associado à sensibilidade humana e a subjetividade dessa relação, reconhecendo a mulher como um ser único em suas singularidades.

\section{REFERÊNCIAS}

1. Waldow, VR. Cuidar. Expressão humanizadora da enfermagem. Petrópolis (RJ): Vozes; 2006.

2. Schraiber LB, Pires D'OAFL, Couto MT. Violência e saúde: estudos científicos recentes. Rev Saúde Pública. 2006 Ago; 40(Esp):112-20.

3. Aliello YV, Estrada LC, Brito YD, Molina LM, Rivero JLP. Violência conyugal em la mujer. Revista Archivo Médico de Camaguey. 2005 Out [acesso 2007 Ago 5]; 9(5). Disponível em: http:/ / www.amc. sld.cu/amc/2005/v9n5/1079.pdf

4. Mattar R, Abrahão AR, Andalaft Neto J, Colas OR, Schroeder I, Machado SJR, et al. Assistência multiprofissional à vítima de violência sexual: a experiência da Universidade Federal de São Paulo. Cad Saúde Pública. 2007 Fev; 23(2):459-64.

5. Oshikata CT, Bedone AJ, Faúndes A. Atendimento de emergência a mulheres que sofreram violência sexual: características das mulheres e resultados até seis meses pós-agressão. Cad Saúde Pública. 2005 Jan-Fev; 21(1):192-9.

6. InoueSRV, Ristum M. Violência sexual: caracterização e análise de casos revelados na escola. Estud psicol. 2008 Jan-Mar; 25(1):505-15.

7. Oliveira PM, Carvalho MLO. Perfil das mulheres atendidas no programa municipal de atendimento à mulher vítima de violência sexual em Londrina- PRe as circunstâncias da violência sexual sofrida: período de outubro de 2001 a agosto de 2004. Semina. 2006 Jan-Jun; 2(1):3-11.

8. Faúndes A, Rosas CF, Bedone AJ, Orozco LT. Violência sexual: procedimentos indicados e seus resultados no atendimento de urgência de mulheres vítimas de estupro. Rev Bras Ginecol. 2006 Fev; 28(2):126-35.

9. Waldow VR. Ocuidado na saúde. As relações entre o eu, o outro e os cosmos. Rio de Janeiro (RJ): Vozes; 2004.

10. Sena RR, Silva KL, Gonçalves AM, Duarte ED, Coelho S. O cuidado no trabalho em saúde: implicações para a formação de enfermeiros. Interface-Comunic, Saúde Educ. 2008 Jan-Mar; 12(24):23-33.

11. Ministério da Saúde (BR), Secretaria de Atenção à Saúde. Departamento de Ações Programáticas
Estratégicas. Área Técnica de Saúde da Mulher. Prevenção e tratamento dos agravos resultantes da violência sexual contra mulheres e adolescentes: norma técnica. Brasília (DF): MS; 2005.

12. Takemoto MLS, Silva EM. Acolhimento e transformações no processo de trabalho em enfermagem em unidades básicas de saúde de Campinas, São Paulo, Brasil. Cad Saúde Pública. 2007 Fev; 23(2):331-40.

13. Sobral V, Tavares CMM, Silveira MF. Acolhimento como instrumento terapêutico. In:Santos I, Figueiredo NMA, Padilha MICS, Souza SROS, Machado WCA, Cupello AJ. Enfermagem assistencial no ambiente hospitalar. realidade, questões, soluções. São Paulo (SP): Atheneu; 2004. p. 65-70.

14. Medina ABC, Penna, LHG. A percepção de enfermeiras obstétricas acerca da violência intrafamiliar em mulheres grávidas. Texto Contexto Enferm [online]. 2008 Jul-Set [acesso 2008 Set 08];17(3):466-73. Disponível em: http:/ / www.scielo. $\mathrm{br} / \mathrm{pdf} / \mathrm{tce} / \mathrm{v} 17 \mathrm{n} 3 / \mathrm{a} 07 \mathrm{v} 17 \mathrm{n} 3 . \mathrm{pdf}$

15. Maia AR, Vaghetti HH. O cuidado humano revelado como acontecimento histórico e filosófico. In: Sousa FGM, Koerich, MS. Cuidar-cuidado. Florianópolis (SC): Papa-Livro; 2008. p.15-33.

16. Celich KLS. Dimensões do processo de cuidar. A visão das enfermeiras. Rio de Janeiro (RJ): EPUB, 2004.

17. Souza AIJ, Erdmann AL. Contribuições para o conhecimento em enfermagem à luz da fenomenologia da percepção de Merleau-Ponty. Rev Gaúcha Enferm. 2006 Jun; 27(2):166-75.

18. Boff L. Saber cuidar. Ética do humano - compaixão pela terra. 9a ed. Petrópolis (RJ): Vozes; 1999.

19. George JB. Teorias de enfermagem: os fundamentos à prática profissional. $4^{\mathrm{a}}$ ed. Porto Alegre (RS): Artes Médicas; 2000.

20. Persegona KR; Zagonel IPS. A relação intersubjetiva entre o enfermeiro e a criança com dor na fase pósoperatória no ato de cuidar. Esc Anna Nery Rev Enferm. 2008 Set; 12(3):430-6.

21. Moreno RL, Jorge MSB, Garcia MLP. Fenomenologia - fenômeno situado: opção metodológica para investigar o humano na área da saúde. Esc Anna Nery Rev Enferm. 2004 Dez; 8(3):348-53.

22. Monteiro CFS, Rocha SS, Paz EPA, Souza IEO. Fenomenologia heideggeriana e sua possibilidade na construção de estudos de enfermagem. Esc Anna Nery Rev Enferm. 2006 Ago;10(2):297-301.

23. Heidegger M. Ser e Tempo. $12^{\mathrm{a}}$ ed. Universitária São Francisco, Petropólis (RJ): Vozes; 2006. 